\title{
Erratum to "Regional atmospheric circulation change in the North Pacific during the Holocene inferred from lacustrine carbonate oxygen isotopes, Yukon Territory, Canada" [Quaternary Research 64 (2005) 21-35]
}

\author{
Lesleigh Anderson ${ }^{\mathrm{a}, *}$, Mark B. Abbott ${ }^{\mathrm{b}}$, Bruce P. Finney ${ }^{\mathrm{c}}$, Stephen J. Burns ${ }^{\mathrm{a}}$ \\ ${ }^{a}$ Department of Geosciences, University of Massachusetts Amherst, Amherst, MA 01003, USA \\ ${ }^{\mathrm{b}}$ Department of Geology and Planetary Science, University of Pittsburgh, Pittsburgh, PA 15260-3332, USA \\ ${ }^{\mathrm{c}}$ Institute of Marine Science, University of Alaska Fairbanks, Fairbanks, AK 99775, USA
}

The publisher regrets that several typesetting errors occurred in the article after the proofreading stage. On page 27 in Figure 5 the vertical axis was incorrectly typeset as "Age (cal yr B.P.)." The corrected figure and its legend are reproduced here.

The spelling of K.E. Trenberth's name for the reference Trenberth and Hurrell (1994) was incorrectly typeset as "Trenbirth" throughout the article. The complete reference should be as follows: Trenberth, K.E., Hurrell, J.W., 1994. Decadal atmosphere-ocean variations in the Pacific. Climate Dynamics 9, 303-319.

In page 21 the keywords were incorrect and incomplete. The complete keywords should be as follows: Keywords: Holocene; Lacustrine carbonate; Yukon Territory; Oxygen isotopes; Aleutian Low; Paleoclimate.

DOI of original article: 10.1016/j.yqres.2005.03.005.

* Corresponding author. Fax: +1 4135451200 .

E-mail address: land@geo.umass.edu (L. Anderson). 

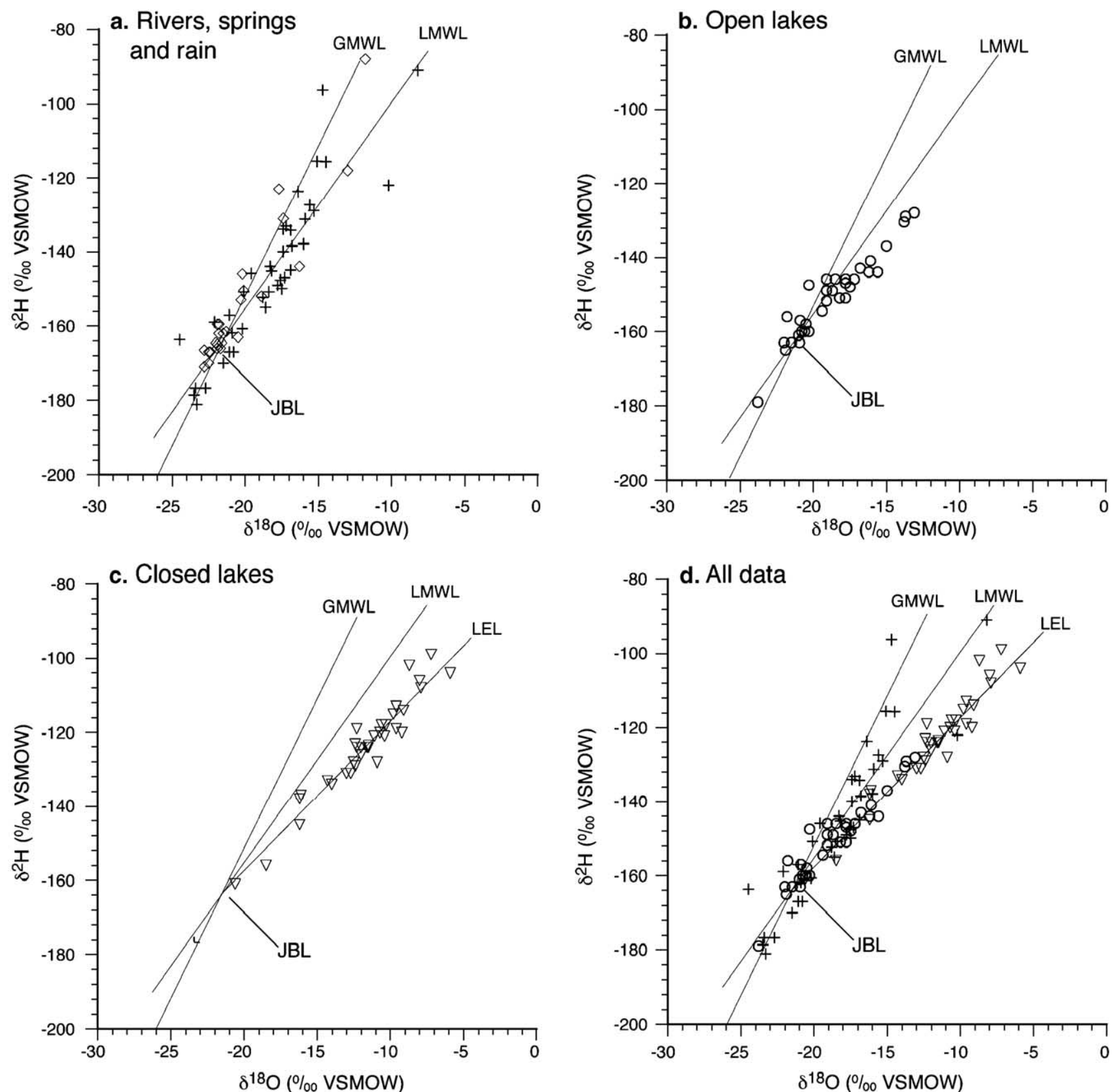

Figure 5. Oxygen and hydrogen isotope ratios of 71 surface water and precipitation samples from the southern Yukon Territory including Jellybean Lake (JBL) (sampling locations in Anderson, 2005): (a) precipitation from Mayo and Whitehorse (crosses) (IAEA/WMO, 2001), and rivers, groundwater or springs (open diamonds). GMWL is the Global Meteoric Water Line (Rozanski et al., 1992). LMWL is the Local Meteoric Water Line, a linear regression of Mayo and Whitehorse data; (b) hydrologically-open lakes (open circles), (c) hydrologically-closed lakes (open triangles). The LEL is the Local Evaporation Line, a linear regression of the lake data; (d) all data. 